Article

\title{
Rural Identity, Authenticity, and Sustainability in Italian Inner Areas
}

\author{
Gianpaolo Basile and Aurora Cavallo * \\ Faculty of Economics, Universitas Mercatorum; 00186 Rome, Italy; gianpaolo.basile@unimercatorum.it \\ * Correspondence: a.cavallo@unimercatorum.it; Tel.: +39-06-88373300
}

Received: 27 December 2019; Accepted: 7 February 2020; Published: 10 February 2020

\begin{abstract}
This paper focuses on the sustainable development conditions in Italian Inner Areas. Italy's Inner Areas are rural depopulated areas characterized by their distance from the main service centers of education, health, and mobility, according to the classification proposed by the National Strategy for Inner Areas in 2012. The inner and marginal areas are recently getting the interest of the market place and agricultural economics, as well as the attention of the regional and cohesion policies of national governments and the European Union. These places provide an intriguing perspective for a broader reflection on European peripheral areas and their development trajectories. The aim of this contribution is to interpret the determinants of the relationships between rural identity and perceptive components of authenticity, in order to understand the mechanisms by which they are positively reflected in socio-economic and environmental use, influencing in turn, the level of sustainability of territorial development. We found a specific role of the rural identity in the catalyzed phenomena of interaction between citizens/community and visitors/stakeholders, through the authenticity effect, identifying them as the basis of the spontaneous, bottom-up emersion of a symbolic platform, which characterizes the identification of a place brand and of the creation of the perception/destination of the inner territories' characteristics. Finally, the paper discusses an Italian Inner Areas project promoted by the common engagement of local institutions and social and economic actors.
\end{abstract}

Keywords: inner Areas; rural identity; authenticity; marketing place; place branding

\section{Introduction}

The Long Slump (2008-2014) which invested the Western countries during the last decade, had a particularly meaningful relapse under the economic and social points of view, as well as in relation to the geographical distribution of the population [1], mainly in the Mediterranean countries of the European Union [2,3], namely Greece, Italy, and Portugal. Here, the economic crisis translated itself into a substantial growth of the outward migration rates and in a reduction of the inward migration fluxes $[4,5]$.

In 2018, the European Union (EU) represented an urban population of $72.1 \%$ of Europe (367 million inhabitants of a total of 508 million). In Italy, the urban population is estimated at 49 million of a total of 61 million, namely $81.1 \%$ : this sets the country as the fifth-largest by urban population, behind Malta (99.8\%), the Netherlands (85.3\%), Great Britain (85.1\%), and Belgium (81.9\%). Furthermore, during the same year, Italy accounted for an urbanization rate of $33.8 \%$ of the entire population-14 million circa, concentrated in the most densely populated areas (middle-sized and metropolitan cities).

In recent decades, European peripheral areas have faced new challenges linked to their role in a more globalized and interconnected world. On the one hand, their socio-demographic as well as economic decline and environmental fragility, on the other, the opportunities related to greater mobility and the role of the technologies of information and communication, which have led to different perceptions on development policies. The development strategies of the peripheral areas 
in Europe address the social, political, and cultural priorities, trying to reverse depopulation and marginalization of these areas, through actions aimed at improving essential services and triggering local development processes.

In Italy, urban policies have been historically characterized by both the fragmentation of different actors in the administration and between different institutional levels, and by the constant demand of adaptation to context-related, economic as well as socio-economics changes. In fact, urban areas, being equipped by major infrastructures providing essential services such as education, healthcare, and mobility, play the role of attractors for the population, for the younger ones in particular. Younger citizens tend to move from rural and coastal areas to cities, causing the growth of youth depopulation and the simultaneous hydrogeological instability with the related soil degradation and consumption.

In Europe, the National Strategy for Inner Areas (NSIA) [6], which was launched by the Italian Government in 2012, is one of the most comprehensive and integrated strategies for tackling the problems of depopulation and low access to services. The NSIA represents a laboratory for integrated rural development and institutional innovation. The process is based on a multidimensional model and builds on experiences of local development in Italy and is being supported by all the main EU funds, as well as national funds.

In the authors' opinion, the NSIA and the role of the Italian experience could constitute an intriguing starting point for a wider reflection on the inner or peripheral European areas and their developmental trajectories, which are facing some crucial issues in the debate on regional studies.

According to the NSIA data, the Inner Areas (IA) cover about $60 \%$ of the Italian territory, hosting a population of over 13,540 million inhabitants, equal to about a quarter of the Italian population divided into over four thousand municipalities [6]. These territories have a territorial capital of exceptional value and diversity, which, however, is largely unused due to the long-term demographic decline that began in the 1950s. The NSIA has the general objective of promoting local development by activating unused territorial capital through development projects. The improvement of the quality and quantity of essential welfare services of education, health, and mobility in the IA is a central pillar of the strategy.

The IA, according to NSIA's definition [6], has three distinctive features. First, they are fragile from a socio-demographic point of view due to the aging of the population. Secondly, they are unstable from a physical and ecosystemic perspective, as a consequence of the insufficient maintenance of their semi-natural capital. Finally, in these places, a significant part of the territorial capital is underutilized or unused. These three characteristics are common to most of the rural territories of Mediterranean Europe, as well as the Central-Eastern ones and the Scandinavian Peninsula. Although these conditions are common to several European countries, none of the EU rural development or cohesion policies or regional policies have promoted an analysis and intervention strategy comparable with the Italian experience (6). In fact, the NSIA currently represents the only intervention model on inner and marginal areas in the EU.

The NSIA strategy pivots on the following themes [6]:

- Practices on defense and usage of cultural heritage,

- Relationship between product innovation and local cultural traditional products,

- Access to land,

- Ecosystem services, and production and alternative management of energy,

- Sustainable farming,

- Prevention of seismic events, and active management of the territory,

- Attraction of a new immigrant population,

- Citizen participation and how they can impropriate instruments to evaluate if choices made are correct, or how to rethink such choices.

Actually, in Italy, 72 pilot project areas exist that are working on the strategy focus. The NSIA's focus is considered in the 2021-2027 European Regional Development Fund (ERDF) for the first time. Therefore, it is forecast that at least $5 \%$ of the ERDF resources available at national level under 
the "Investment for jobs and growth goal", other than for technical assistance, shall be allocated to integrated territorial development in non-urban areas with natural, geographic or demographic disadvantages, or which have difficulty accessing basic services. Out of this amount, at least $17.5 \%$ shall be allocated to rural areas and communities taking into account provisions of a Smart Villages Pact to develop projects such as rural and remote areas.

In the IA, along with the accelerating demographic crisis for decades, there are robust signs of civil, entrepreneurial, administrative and cultural vitality, in which the rural and agricultural dimension plays a central role. As an example, the stationary share of young farmers, which instead collapsed in Italy in a decade by 30\% [6]. These characteristics, with diversified trends, distinguish all the IA. As part of the process initiated by NSIA, the process of defining, identifying and mapping the IA represented a long phase of theoretical and methodological investigation [6]. Nevertheless, statistical data at present are not comparable with other European countries and with Eurostat data, they only represent the processing for the Italian case only.

The socio-demographic and economic decline and environmental fragility, as well as the opportunities linked to tangible and intangible territorial characteristics, require a model based on a systemic vision for drawing up strategies and operational actions. The development strategies have to address the social, political, and cultural priorities, trying to reverse depopulation and marginalization of these areas, through actions aimed at creating and improving endogenous (i.e., cultural, social, and economic awareness in the local communities) and exogenous (i.e., between territorial expressions and relevant stakeholders as travelers, tourists, investors, migrants) relations.

The NSIA has catalyzed the launch of many experiences in the IA of social and institutional innovation, as well as on forests sustainable management, renewable energy and a green economy, craftsmanship, rural tourism, active citizenship and participation, cultural and social initiatives.

However, few studies have explored the relationship between territorial identity and sustainability in its multiple dimensions as boost factors and consolidation of these experiences [6]. Furthermore, there are no scholars that have identified a model that focuses on the relationships between community and places in the IA as factors of rural identity.

To fill these gaps, the paper shows an interpretative framework of the territorial dynamics and of territorial management finalized to development (i.e., repopulation, unemployment, education level, healthcare, maintenance of natural capital) effects, in socio-economic and environmental sustainability terms, deriving from the relation between the identity traits of a territory and the stakeholders authenticity perception (i.e., institutions, local actors, tourists, visitors, travelers).

In the framework, the authors focus the attention:

- $\quad$ on the meaning of rural identity in the IA and its role in starting sustainable conservation and valorzation processes;

- to aggregate the concept of authenticity as the driver of the existing dynamics (or to be built) in rural places among local stakeholders.

- $\quad$ on the precondition for stimulating actions aimed at social, economic, and environmental sustainability revitalization of the IA areas.

Thus, the dimension of sustainability is considered of long-lasting value, both structural and semantic, between the identity proposed and authenticity perceived of a territory. The sustainability, as considered in this work, is the expression of the relationships between the assets of the territory, the communities that inhabit it, and the involved stakeholders with the relative socio-economic and environmental repercussions. Therefore, we consider identity as a factor of social cohesion of a community, or rather as an internal dimension to the community and to territorial relations, which establishes the presupposition of sustainability.

The paper is an expression of a constructivist approach, which sustains that the identity, composed of tangible and intangible (memories, histories) elements, represents the social and cultural processes, born of the relations between components of the territory. It continuously creates, in the domain of 
further relations, the perception and experience, bringing out authenticity from stakeholders. Therefore, authenticity is the recognition of the trait of originality, of production and the adequate usage of the product, of the "compatibility" evaluation between product, time, and place of its perceived origin [7].

The authenticity, for these reasons, varies on the basis of different factors, including: time, planned usage of product, knowledge-base, type of product, and the person evaluating the characteristics.

The problem of authenticity arises in different categories of products. However, it is prevailing in a borderland, where there is the interaction between people and products from two or more cultures, societies, or countries. In this interpretation, it is read in the dimension of urban-rural relations, center-periphery [8].

The paper is organized as follows: in Section 2, we discuss the objectives and approach; in Section 3, we present the conceptual framework, discussing the role of the territorial identity in relation to the rural areas and as a factor of civicness, thus the authenticity and the value of the rural brand. In Section 4, the work focuses on the experience of Madonie, studied on the desk, to discuss the presented framework. The Madonie Mountains in Northern Sicily are a pilot project area of NSIA, which is further discussed in Section 5 . The paper is concluded by summarizing the considerations.

\section{Objectives and Methods}

This work focuses on the nexus between rural identity and perceptive components of authenticity in order to understand the positive relapse of the territory's changes and fruition influencing sustainable development.

The questions are:

- $\quad$ is it valid for a nexus between rural identity and authenticity perception?

- what processes allow you to recover the rural identity of a place? How do these reflect on civicness and community cohesion, and then, through a recursive process, on authenticity (in the case of the spontaneous processes) and destination (in the case of a built process)?

- could rurality and authenticity be considered as the preconditions to catalyze sustainable local development processes?

The paper focuses on a conceptual framework that tries to show that positive relations could exist between territorial identity, stakeholder authenticity perception and, finally, social and economic sustainability, aimed to achieve better social and economic community conditions.

According to the authors, this "recursive" phenomenon, if based on an active role of the communities and their relationship with natural and anthropic resources as an expression of identity of the territory, is able to stimulate "authentic" perceptions useful to support economic development, which is not apart from the social one. To achieve this goal, the authors illustrate a Southern Italian territory example, that is a pilot project of NSIA, characterized by conditions of structural, social, and economic decline, but also by established and recognized traditions, cultures and natural resources, which helps to show the existence of the following relationships, as shown in Figure 1:

- Identity and authenticity.

- Authenticity and sustainability.

- Sustainability and identity (adapted).

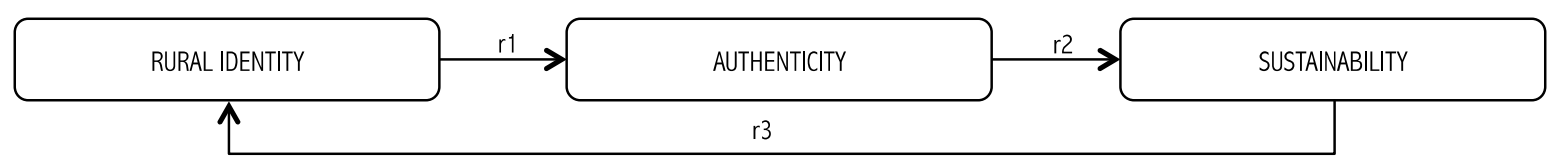

Figure 1. The recursive process: rural identity-authenticity-sustainability. Source: own elaboration.

The paper has a theoretical approach. The authors have undertaken an extensive literature review in order to build an extensive conceptual framework that holds the rural identity together and places 
branding through authenticity. Later, the work focused on analyzing NSIA pilot projects $[6,9]$ to apply the framework.

The approach attempts to transfer the understanding of places as "continually produced and reproduced in interaction with their stakeholders and surroundings" [10]. For this reason, we argue that identity is based on social relations and people-practices, and it is a circular process between community members and stakeholders. So, in this way, the identity is an on-going relationship between civicness and territorial characteristics and stakeholder perceptions (i.e., authenticity and brand). If the brand is not based on identity, then the relational efforts can only lead to authenticity and brand aliens, particularly to its internal audiences and to social and economic sustainability [11,12]. Therefore, where the structural and functional relationships that link the three dimensions interrupt or fragment, the crisis of the territorial system is determined. This crisis, in inner and peripheral areas, where social, economic and environmental balances are more fragile, generates depopulation and abandonment processes $[13,14]$.

As already highlighted above, the approach, in order to invert the socio-demographic and labor supply trends in the IA, stimulates the creation of aggregations between small countries in the inner areas, with purposes in the following sectors: health, mobility, and education. The territory lends itself to a process of re-emergence of identity (social and economic) based, from a structural point of view, on the tangible and intangible components and on the agents that define its status; from a systemic point of view, on the identification of meta-objectives and on the relative possible conditions (interactions between the components and agents of the territory) to be obtained.

With the aim of reasoning around the empirical dimension of the framework outlined, we focus, by way of example, on a territorial experience of Madonie. The data sources, linked exclusively to the Italian case studied on the desk and without analysis in the field, are penalized by the scarce updating and by the difficulty of availability at the municipal level.

Therefore, the approach was used to explore and understand a diversity of social and public policy issues, either as an independent research strategy or in combination with some form of statistical inquiry. The wider use of qualitative methods has come about for a number of reasons but is underpinned by the persistent requirement in social policy fields to understand complex behaviors, needs, systems, and cultures.

The paper has focuses on the case of Madonie in order to capture best practices within a sustainable perspective in light of Agenda 2030. Therefore, these development trajectories address some crucial issues in the regional studies debate as well as in future EU cohesion policy.

Desk research or document analysis usually forms part of a social policy research project (and occasionally is confined to these approaches alone), it is more usual to find that new data is collected. In the present work, the researchers had some difficulty in finding data to analyze because in statistical studies, the area observed is aggregated at the province level.

\section{The Conceptual Framework}

\subsection{Territorial Identity and Rurality}

In the IA, agriculture plays an important role in terms of added value and employment. According to Van der Ploeg [15], rural development as a multi-level and multi-actor process can be carried out at a single-family farm level. At this level, rural development emerges as a redefinition of identities, strategies, practices, interrelations, and networks.

In this sense, in particular in the complex Italian context, while on the one hand compared to the past, research efforts have been multiplied to investigate the possible intervention strategies for management and planning; on the other hand, we need to investigate the causal links that connect the successful experiences in which the reverse of crisis dynamics and territorial abandonment was determined in favor of repopulation and valorization. 
The reduction of social exclusion and citizenship rights, economic weakening, the critical issues in primary education, health care, and transport services are just some of the causes of territorial fragility $[16,17]$. The profound diversity of these territories has influenced the terminology with which they are defined with respect to the past. As Battino and Lampreu [13] point out, there is difficulty in identifying and, therefore, enhancing the values of these places. The complexity of the characters of the mountain areas or of the agricultural and rural areas, or even the inner or disadvantaged areas, while recognizing the centrality of agricultural activities as factors of care and territorial protection, are reflected in the difficulty of analysis and identification of methodological approaches to analyze and recognize them.

Between territorial identity and sustainability, there is a relationship of reciprocity and interdependence [18]. A consolidated territorial identity represents the outcome of a process of accumulation of social capital, which is an immaterial resource for development. This is followed by the sense of belonging and self-recognition of local actors, whose role in rural areas is central [19]. Thus, territorial identity is a basic resource for the resilience of territorial systems, which is an important component to guarantee territorial development and territorial governance.

The Italian context is particularly interesting for at least three reasons. First of all, the polycentric character that characterizes the country and the extreme complexity of its physical, historical, socio-economic, settlement-related, cultural and environmental features, gives back a variety of landscapes, climates, agriculture, and food, which is reflected in a plural national identity [20] and in its complex territorial declinations.

Socio-economic analysis, particularly the one of the agricultural-economic matrix, has historically been constructed by a number of interpretative schemes aimed at reading the complexity of the matrix of rural-urban relations, of the productive characteristics of the institutional frameworks, and of the evolutionary features of the regional development [21-24]. However, the second reason of interest is placed with respect to the Italian frame, these representations have faced in the last decade difficulties in restoring effective readings of national territorial aggregations [25]. The most well-known analytical paradigms of Italian territorial development-the North-South divide, the "three Italies" [26], the "industrial triangle", the district dimension [27] and the spatial interpretation of rural-urban relations: the "pulp and bone" [22], the mountain and the plain, the widespread urbanization [28] —have experienced in the last twenty years a progressive difficulty in reading the processes of reconfiguration in progress, the fragmentation and the structural and spatial differences. This happened in the context of a growing metrophilia [29], which saw an ever-increasing focus by Italian and European scholars on urban areas [30].

The third reason that places the Italian context as an intriguing point of view, is linked to the fact that in recent years, the country has been configured in Europe as a laboratory for the application of place-based policies, with the implementation of the NSIA [6,31] providing a broader reflection on peripheral areas in Europe and their development trajectories, which addresses crucial issues in the regional studies and cohesion policies debate.

In recent decades, Europe's peripheral areas have had to address the challenge of re-inventing themselves and to undertake the task of finding their place in a more globalized and interconnected world. A number of new opportunities have been furnished by increased mobility and the greater importance acquired by information and communication technologies, which have resulted in different perceptions of how development policies are interpreted and designed.

The conceptual and implementation design of the NSIA has focused on the role of essential services as citizenship rights, considering them a variable dependent on the level of development.

The implementation path of the strategy on one hand, has given rise to a multiplicity of design experiences in some inner territories [14]; moreover, as has been broadly documented by some scholars [9], the NSIA's application has favored a new focus on the search for new atlases, new "horizontal" representations [25] aimed to reveal the diversity of territorial frameworks. 
Based on these elements, we argue a reflection on the rural identity dimension: a survey that tries to explore agricultural and rural phenomenology in search of its identity dimension and its role in the framework of sustainable territorial development.

The role of rural identity in the IA is connected to the role that agricultural activities play in driving sustainability processes. This is unstable from an environmental point of view as a consequence of insufficient maintenance of their semi-natural capital and human landscapes-mainly farming — besides the under exploitation or the underuse of territorial capital, which is strictly related to the disappearance of agricultural activities and their multifunctional role [15].

The cultural dimension of agricultural activities, and more generally, of rural areas, is a topic that is experiencing a growing interest on the part of scholars [32-36].

While on the one hand, it is evident that agricultural activities are conditioned by territorial characteristics in terms of availability of environmental resources (water, soil, forests, energy), they constitute the constraints of agricultural activity and condition the organization and structure of farms, like the role of farming itself in territorial balances.

Despite the fact that technologies have allowed these natural constraints to be overcome at least in part (for instance irrigation, or mechanization, or technologies in general), the dominant features of the territorial agricultural systems still remain linked to the environmental characteristics of a specific place. Not only that, but the agricultural activities practiced in inner territories are significantly different from that of the hilly and flat areas since there they developed exclusively the productive activities that are best suited to the characteristics and the endowments of these territories. In this direction, there is a cultural identity dimension linked to the complexity of the places themselves, for instance, the agriculture as a productive activity that uses natural resources in a sustainable way for the future of inner territories.

Agricultural activities have also helped catalyzing numerous initiatives related to the liveliness and resilience of these areas [37]. Some experiences include tourism development in rural and inner areas, forms of governance in the interaction between private action and public policy, and experiences of social innovation. These processes are often studied separately from different disciplinary fields related to an agrarian economy, marketing, regional economy, up to the sociology of the territory. However, cultural issues are transdisciplinary and deeply interconnected and influence the vitality and competitiveness of rural systems $[15,35,38]$. Besides, experiential tourism expresses a demand for culture, authenticity and typicity, which is an occasion for identity, civicness, awareness, and responsibility on the part of local communities. Exploring the meanings linked to the rural identity dimension and the cultural value of agriculture, in relation to other productive activities such as craftsmanship and sustainable tourism in local territorial systems, can become a useful perspective for building "place sensitive" territorial policies $[39,40]$.

In the district literature, Becattini [41], in an essay of some years ago, studied the role of agricultural activities in the organization of the territory. Becattini, describing the characteristics of agricultural production, underlines the role of local societies and postulates the notion of a rural local system, namely those areas in which the socio-economic context is characterized by a complex of productive activities strongly linked to the valorization, conservation, and reproduction of "renewable and historical" natural resources [41]. The productions derived from these systems are configured as "integrated specialties" able to offer a basket of goods and services capable of satisfying a wide cluster of needs. Here, the producers (farmers, artisans, service providers etc.) are linked to the community in a sort of stable solidarity where the costs and benefits of production are shared. The same approach had been proposed by Romano [42] who, referring to the rural dimension, had declined sustainability in local development systems as contexts characterized by production activities and valorization of renewable natural resources on a territorial basis, highlighting how in these cases, the territory itself represents the fundamental core of the contextual knowledge of the system. Thus, the link between the environment and rural communities provides productions (precisely integrated specialties), which are the result of synergic links between activities that have a specific territorial dimension [43]. 
Craftsmanship, multifunctional agriculture, agritourism and rural tourism, social farming, catering, traditional and cultural events, management and care of wood and landscapes represent activities that are deeply integrated with each other and exogenous to the local rural system [35].

\subsection{Identity as a Factor of Civicness}

In the discussion developed here, the role of the local institutional dimension and of the community, namely the centrality of local actors, is strongly affirmed. The key subjects are the networks of families, farms, and firms, considered as a whole as a complex system where the role of institutions is a focus point, integrated into what Becattini and Zorini [41] define as "a life project". Therefore, productive activity is at the center not only of business choices but also is embedded in a place and its community, thus covering the role of social capital. It follows that the objectives of the actors involved can be placed as key to the sustainability approach and specifically in SDGs (Sustainable Development Goals) perspectives. But not only that, the role of belonging to a territory and its conservation from a sustainable development perspective becomes the declination of its identity matrix. The value dimension of the community displays itself in the (self) recognition of a place, a landscape, a product, or a service.

The community, like the complex of families, businesses, organizations, and institutions that become development agents adhering to a common territorial vision-a common project-of that territory, declines an idea of identity. This identity is generated and transmitted by the culture and traditions of the territory and is contained in the products and services offered. The latter, therefore, is characterized by: having an adequate level of quality, deriving from sustainable production processes, and is guaranteed by the rules and practices of the place. Identity, in this reading, is the outcome of the sharing of values recognized and shared by the community, which concerns the relationships between productive activities and the use of natural resources, the knowledge and the diffusion of the conditions of production and reproduction of productive, not dissipating activities. The "conscience of place" of Becattini [44], becomes a condition of clumping of a community, against the pulverization (increasingly smaller dimensions of the settlement and social phenomena) and the fragmentation of territorial relationships.

This type of relationship is peculiar in territories with a high environmental and historical-cultural landscape value. In these, the tourists as well as the visitors, consumers, investors, and stakeholders' demands are offered a basket of agricultural products, local craft products, and cultural and landscape services. Tourists, visitors, consumers, investors, and stakeholders will be immersed in this cultural dimension, perceiving the values and practices of territorial contexts in the connection between the local community and the productive fabric of a social structure [9].

From this perspective, the idea of subsidiarity and co-production between public and private actors, economic and social values, becomes a support engine from the perspective of a welfare system linked to rural and internal areas able, within the framework of social innovation processes, to determine new shared responsibilities and greater civicness [35,37].

In this development, the rural identity of inner areas becomes an element of social cohesion, which directs the government of the territory and its valorization, and incorporates a deeply dynamic dimension. The territorial transformations that can define new local instances find new compatibility and new evaluations of the lines of political, design- and planning-related intervention.

The topic of territorial identity has been long discussed by a seminal contribution of Cersosimo and Donzelli [45]. The authors find an ideal analytical framework in rural contexts, focuses on the dialectical relationship that links the recognition of environmental resources and historical-artistic resources to territories as markers of identity. Scholars decline the identity base not as organic differences or as static specificities, but as the set of rules and practices through which a community, belonging to a given context, has built its internal relationships. Identity, therefore, stands as a "factor of civicness", as "the degree of social cohesion of a community, the strength of the bonds in it, the degree of fluidity and, therefore, of internal trust, of which a community is capable" [45]. In this sense, the rural identity is 
configured rather than as an outcome or as an initial condition, as a long-term goal, or rather, a dynamic, open and participatory social process, through which the communities choose the distinctive traits in which they believe characterize the territory they inhabit and transform, in view of a shared project, based on local knowledge, skills and resources, and also in relation to natural factors. In this reading, the construction of identity is directed towards a self-sustainable project [18], which allows local communities to inhabit their territory in a conscious and responsible way, determining the conditions structuring the territorialization process and possible re-territorialization [33].

Social cohesion helps to foster collaboration and exchange mechanisms between local actors and communities. Thus, the territory becomes a relational space that the community perceives itself by establishing the basis for the affirmation of that dimension of authenticity that lays the foundations for territorialization. In this direction, it follows that local development, like policies and their effectiveness, can influence neighboring regions through a positive or negative spillover mechanism [46].

It is evident that the sense of belonging read in this form is associated with the concept of network and in addition to determining trust, but above all, self-confidence of a territory and of the community inhabiting it, specifically in inner places, it fosters cooperation and consolidation of social capital and with them a net reduction in transaction costs, namely information and contractual costs [41,47].

\subsection{Authenticity as a Development Variable}

Authenticity is a complex concept, the subject of study in various scientific areas such as sociology, anthropology, psychology, economics, marketing, and others. Over the years, the concept has been associated with terms such as "genuine", "real", "to trust", "original" and other synonyms.

Indeed, the distinction between authentic and non-authentic is not always clear, as the meaning is not based on a static and hermetic understanding, but is mainly entrusted to experience, so as to be connected to the connotation of subjectivity and the relative level of perception of the recipient [48-51].

In the domain of territory development, and particularly in tourism, authenticity is represented as a key construct that evokes the experiential nature of tourist behavior, the result of interactions with the components/identities of the territory and the relations already between them. This is confirmed by the increasingly growing trend of the tourist to search for experiences resulting from the purchase of products that are an expression of the territory, of the use of services or of the "spontaneous/unplanned" interaction with territorial components (residents, natural elements, etc.).

Although the tendency to create and plan more or less spontaneous authenticity conditions is growing, it is widely recognized in the prevailing literature, that the meaning is strongly linked to subjectivity and the relative evaluation of the researcher [51-55].

In this regard, the concept of identity, as interpreted in this work, does not represent a historical-cultural weight that is destined to mark any designing and planning effort. Instead, identity will be interpreted as one of the many conditions of possibility of presence; therefore, not something given in absolute terms, but a dynamic, unstable and self-constituted character, the result of social relations between the components of the territory, which emerges in "relation to other" in order to clarify a "difference from oneself" and not to define a "border between". In this regard, the philosopher Deridda (... ), in the conceptualization of the metaphysics of presence, defines the "différance" as a connotation of the presence of an individual, of a community in relation to the other, in order to identify the conditions of influence and not of separation.

This condition is widely present in the conception of Europe as well as in the cases of application of the NSIA, where young start-uppers and territorial institutions redesign the role of identity as a condition that, in relation to stakeholders, expresses an adequate platform to the new environmental and social needs of the territory, so as to act as a response to the 17 SDGs covered by the Agenda 2030 adopted by the United Nations.

In the domain of territorial management and marketing, therefore, the concept of authenticity is not seen as antithetical to the effort of creating opportunities to be offered to a target, but rather becomes a functional characteristic, especially when the objectives are to give stimulus to the tourism sector. 
Many scholars have tried to deepen the concept by classifying their representation in existential and object-based terms [56-59]. The first form of authenticity characterizes a "social" tourist, more inclined to learn and live everyday life experiences; the other one can be defined as the expression of an "aesthetic" tourist, also interested in perceiving artistic and cultural elements through the purchase of craft objects and more. This attempt was punctually resolved in a difficult, and often forced distinction that instead culminated in the role of authenticity as a correlation both of stimuli to the visitor to the choice of a place, to that of support to the experiential behavior in the phase of the fruition of the same place [60-63]. So much so that authenticity could be considered as a perceptive effect of the rural identity that the visitor or tourist develops as a result of the experienced fruit, in turn, of the relationships lived with the identity traits of the territory [64], as shown in Figure 2.

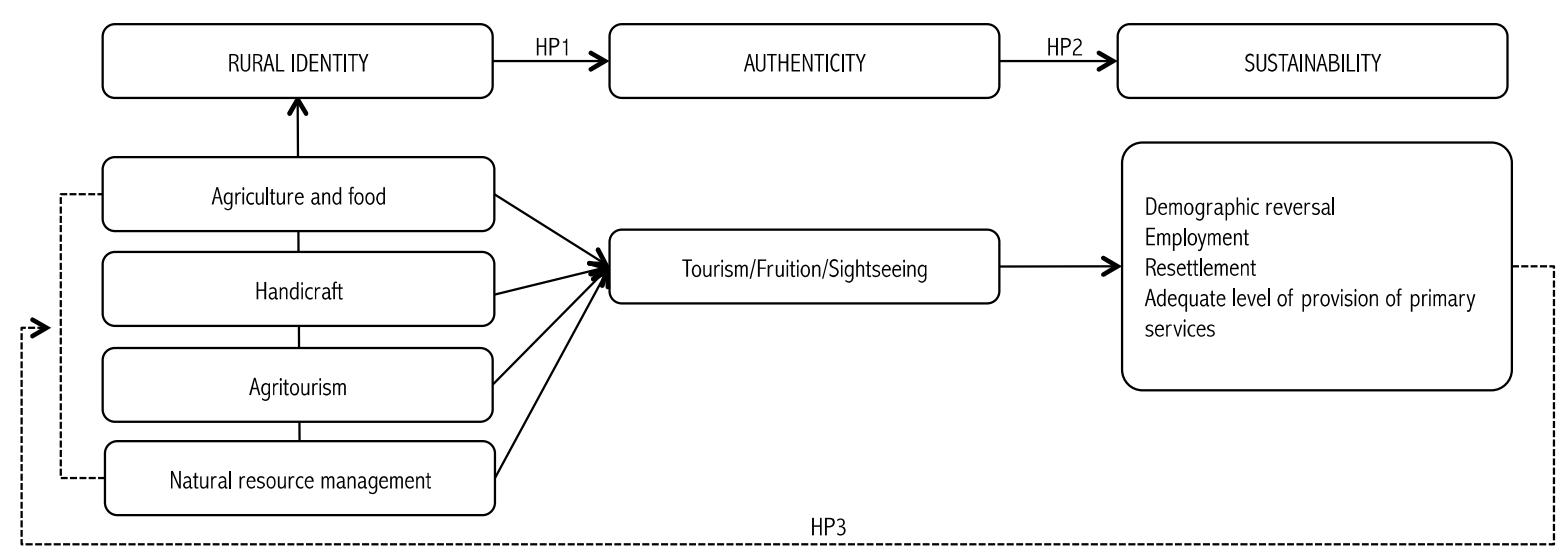

Figure 2. Rural areas sustainable development framework: a focus on agriculture. Source: own elaboration.

Costa and Bamossy [7], in their work on the role of authenticity and its perception, note how consumers suspend disbelief in their assessment of authenticity in some situations. They are aware of the fact that some of the elements used are "real", while others are replicas or synthetic products used in the construction of a space or a product that is evocative of a condition of authenticity, whose evaluation by consumers depends on the context and involves issues of time and space. Furthermore, there is a clear dialectical interaction between what the marketer intends and what the consumer is willing to experiment. It follows, therefore, a joint production of place-consumer involvement, both co-producers in the construction of experience and the perception of authenticity as the outcome of the experience itself. Of course, for the purposes of loyalty, that is, of maintaining over time the relationship between tourist and place, or of word of mouth dynamics, the level of coherence between lived experience and expectations plays a predominant role [65-68].

\subsection{Rural Brand as Emerging Property}

The meaning of the brand and the role it plays in the survival/development of a territory, specifically in the IA, has been debated for decades by both researchers and practitioners. In any case, they all seem to agree that at the base, there is a semiotic meaning to be communicated in the realizations of relational activities [69].

In this regard, Zencker and Brown [70] define the place brand as a "network of associations in the mind of consumers, based on visual, verbal, and behavioral expressions of a territory, which meet the objectives, values, and culture of local stakeholders". On this basis, the place brand can be defined as the selective narration of a territory, or part of it, which contributes to creating relationships with a defined target. In fact, while on the one hand, the brand expresses the signification of the distinctive characteristics of the territory, on the other hand, it represents a dynamic platform that is fed by 
the effect of exchanges, negotiations, in terms of value and information, which occur among the agents involved.

The brand, therefore, plays a mediating role between the territory—understood as a set of values, culture and tangible and intangible characteristics —and its agents and its recipients, also an expression of cultural characteristics and values. Therefore, it can be considered as space, a symbolic and social platform that represents characters, values that result from constant and simultaneous interactions between its components and those of the interlocutors.

The definition of the brand always depends on the result of a process aimed at creating a semiotic and social space, which represents for its creators an expression of identity and an environment which cooperates to find common values with its recipients [71].

According to these considerations, the brand can be defined as a property emerging from bidirectional relationships aimed at satisfying the needs of the actors involved, within an interactive space, not objectively definable, and which cannot always be managed.

This property is characterized by a community, which is an expression of cultures, values, languages object of interactions with social actors carrying different objectives, as shown in Figure 3.

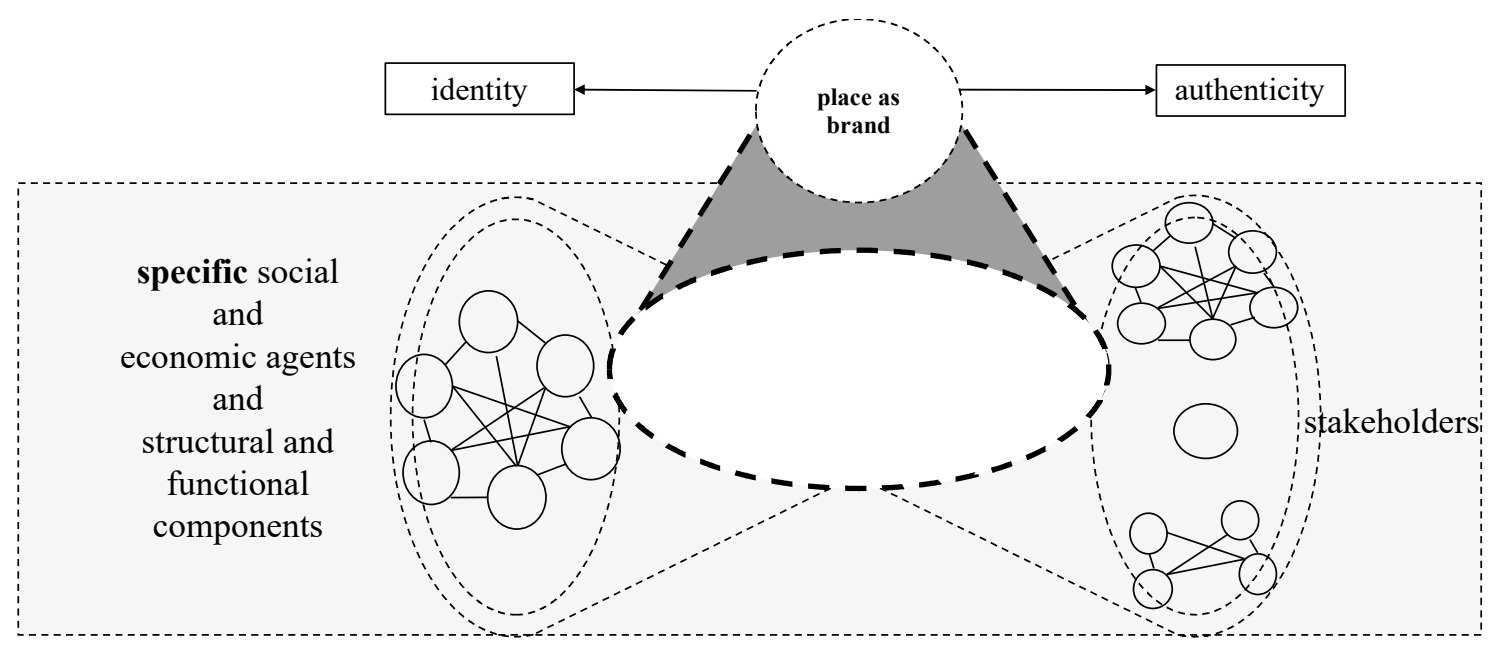

Figure 3. Brand as an emerging property. Source: own elaboration.

The aforementioned form of mediatization of the territory/brand, typical of the post-modern era, risks reducing the legibility of the origin of products and services, leaving the field to an imaginary space that is difficult to manage for marketing and communication professionals. The purpose of this space is to allow the interlocutor/recipient to build a mental mapping of the completion of processes concerning the territorial system [72].

We can say that, from a symbolic point of view, the brand-seen as an emergent property of a self-organizing system-brings with it the distinctive characteristics of a complex system, or of a specific subsystem, and emerges in evocative terms to play a role as a social actor. This role is itself adaptive due to the behavior of the actors who interpret it. It is able to create the conditions of interaction between many social actors, represented by visitors and members of the territory, in order to meet the needs of the latter.

The role represented so far can be achieved quite naturally if the brand, in addition to expressing the cultural and semantic platform, also succeeds in faithfully representing the identity of the system, neglecting the differences between identity and image. This condition leads first to the creation and then to the emergence of meeting spaces that show an experiential value, where a process of co-creation and adaptation between the interacting systems naturally occurs. History, memory, and the archaeology of knowledge (à la Foucault), therefore represent the cognitive basis that allows a system to interact adequately with the contexts of reference, while developing dynamics of mutual adaptation and transfer of knowledge useful for having such relationships last over time. 


\section{The Italian NSIA's Experience: Madonie's Project}

There were 72 pilot areas selected by the process envisaged by the NSIA launched towards the end of 2016, and about twenty projects out of the total are in a more advanced implementation phase which allows the start of a sort of balance of the experiences carried out.

The case of Madonie has been identified among the twenty most advanced pilot projects of NSIA $[9,32]$. We decided to choose this area due to the value of the strategy promoted and the related actions.

Firstly, the intervention project developed in Madonie by local stakeholders assigned a key to agriculture and rural identity and this was very important for reasoning and validating our approach.

Tackling the social issue, the project shows positive effects in the innovative application in the fields of energy, education, and the agrifood chain [73]. In addition, the demographic decline of Madonie has its origin both in the difficult accessibility to essential services and in their quality, and in the scarce employment opportunities. In this sense, the Madonite project has launched new processes that show signs of vitality, with a significant role for young people, particularly in the agricultural sector, and this element was central to our reflection.

The area involves the following 21 Sicilian municipalities located in the Madonie area, in the north centre of Sicily: Pollina, San Mauro Castelverde, Castelbuono, Gratteri, Isnello, Collesano, Polizzi Generosa, Petralia Soprana, Petralia Sottana, Castellana Sicula, Bompietro, Blufi, Salso Geraci Siculo, Gangi, Alimena, Scillato, Caltavuturo, Sclafani Bagni, Montemaggiore Belsito, Aliminusa, and Caccamo (Figure 4).

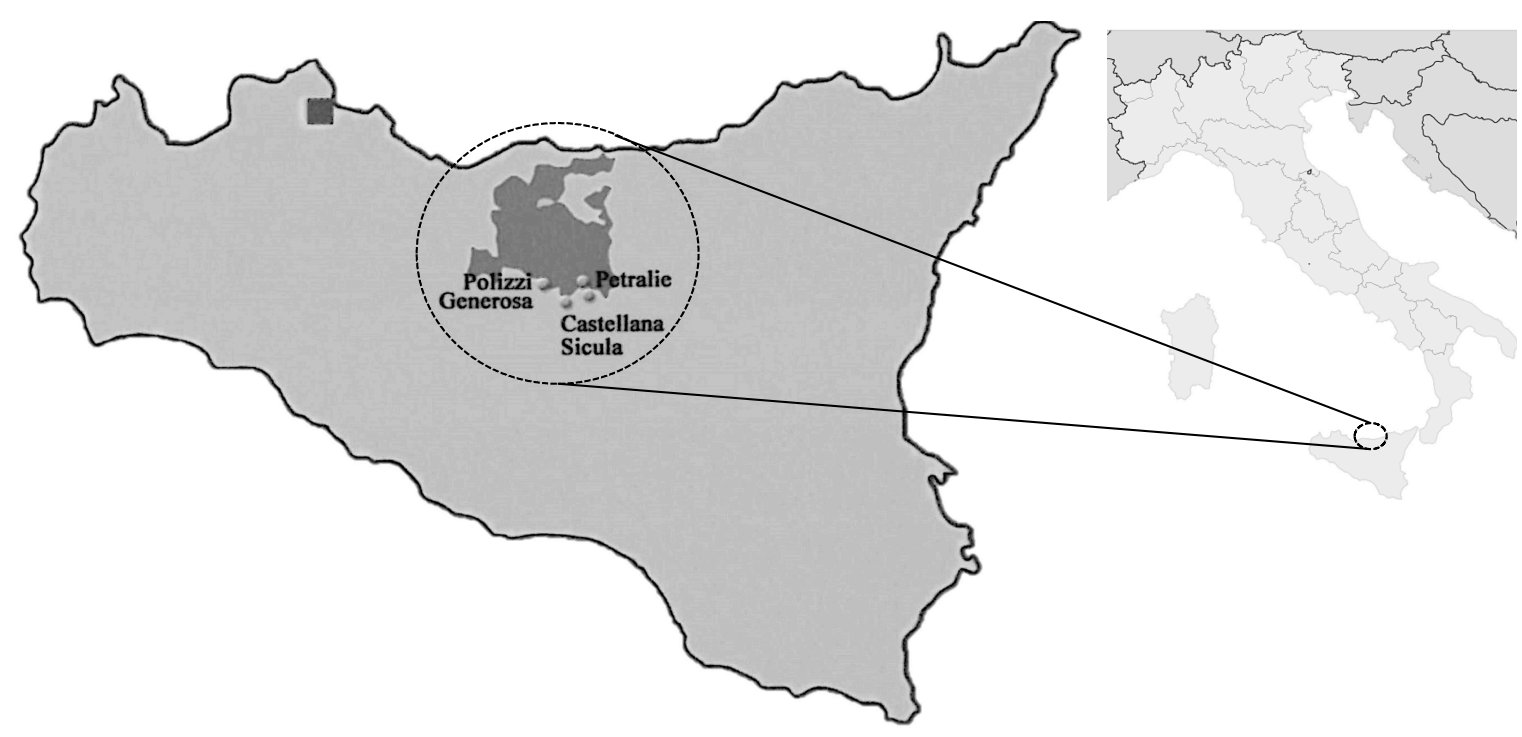

Figure 4. Geographical map of Madonie's project. Source: own elaboration.

Table 1 summarizes the main demographic and socioeconomic characteristics of the Italian IA compared to the national context. The data shows the dynamics of demographic decline, and the problems of the key welfare services (i.e., accessibility, education, health). Table 2 summarizes the agriculture and food variables and shows the weight of agriculture in the local productive systems of the IA and in particular, of Madonie's case. Table 3 focuses on the main economic and tourist features of the IA compared to the national and local context. The framework offered by the data shows the specificity of the Italian case and the relevance of the Madonie experience, which exemplifies in approximately 20 NSIA-related projects that show relevant results, the role of rural identity in addressing local recovery processes. 
Table 1. Socio-demographic variables of Inner Areas (IA) in Italy and the Madonie case.

\begin{tabular}{lccccc}
\hline \multicolumn{1}{c}{ Main features } & Madonie & Sicily IA & Sicily & Italy IA & Italy \\
\hline Number of Municipalities (2011) & 21 & 291 & 390 & 4181 & 8092 \\
Number of Municipalities (2017) & 21 & 291 & 390 & 4115 & 7998 \\
Population (2017) & 63,396 & $2,052,825$ & $5,056,641$ & $13,266,147$ & $60,589,445$ \\
Surface (sq.km) & 1728 & 18,959 & 25,832 & 180,115 & 302,703 \\
Population density (inh/sq.km) & 36.7 & 108.3 & 195.7 & 73.7 & 200.6 \\
Variation of population (1971-2011) & $-25.6 \%$ & $-0.9 \%$ & $6.9 \%$ & $4.6 \%$ & $9.8 \%$ \\
Variation of population (2011-2017) & $-4.5 \%$ & $-0.7 \%$ & $1.1 \%$ & $-0.2 \%$ & $1.9 \%$ \\
Foreign residents (2017) & $2 \%$ & $3.9 \%$ & $3.7 \%$ & $6.5 \%$ & $8.3 \%$ \\
Percentage of foreign residents (2011-2017) & $54 \%$ & $51.7 \%$ & $51.3 \%$ & $20.3 \%$ & $25.2 \%$ \\
Digital divide 1 (2013) & $35 \%$ & $55.1 \%$ & $67.3 \%$ & $46.3 \%$ & $65.4 \%$ \\
Accessibility ${ }^{2}$ & 55 & 40.6 & 37.9 & 37.3 & 20.7 \\
Municipalities with primary school (2017) & $100 \%$ & $99 \%$ & $99.2 \%$ & $77.8 \%$ & $83.3 \%$ \\
Municipalities with secondary school (2017) & $38.1 \%$ & $39.9 \%$ & $41.8 \%$ & $16.4 \%$ & $18.8 \%$ \\
Health ${ }^{3}$ & 21 & 18 & 16 & 23 & 17 \\
Union of municipalities (2013) (\%) & $81 \%$ & $50.5 \%$ & $45.9 \%$ & $24.3 \%$ & $24.7 \%$ \\
\hline
\end{tabular}

$1 \%$ population connected to broadband $>20$ mbps. ${ }^{2}$ Average distance in minutes of the municipalities from the nearest city weighted by the population. ${ }^{3}$ Time (in minutes) between a telephone call to the Operations Center and the arrival of the first emergency vehicle. Source: own elaboration on NSIA data.

Table 2. Agriculture, Food and Environment Inner Areas (IA) in Italy and the Madonie case.

\begin{tabular}{|c|c|c|c|c|c|}
\hline Main features & Madonie & $\begin{array}{c}\text { Sicily } \\
\text { IA }\end{array}$ & Sicily & Italy IA & Italy \\
\hline Utilized Agricultural Area (UAA) (2010) & $58.1 \%$ & $55.6 \%$ & $53.7 \%$ & $39 \%$ & $42.6 \%$ \\
\hline Change of UAA (1982/2010) & $-3.4 \%$ & $-17.5 \%$ & $-18.1 \%$ & $-20.9 \%$ & $-18.8 \%$ \\
\hline Change of UAA (2000/2010) & $9.7 \%$ & $7.3 \%$ & $8.4 \%$ & $-3 \%$ & $-2.5 \%$ \\
\hline Share of young farmers on total farmers (2010) & $10.9 \%$ & $12.1 \%$ & $11.6 \%$ & $10.4 \%$ & $9.8 \%$ \\
\hline Change of young farmers $(2000 / 2010)$ & $-3.3 \%$ & $-26.8 \%$ & $-26 \%$ & $-33.5 \%$ & $-36 \%$ \\
\hline Livestock breed on total farms (2010) & $16.5 \%$ & $8.1 \%$ & $7 \%$ & $14.7 \%$ & $13.4 \%$ \\
\hline Share of pasture and meadows (2011) & $35.5 \%$ & $27 \%$ & $23.1 \%$ & $36.7 \%$ & $26.7 \%$ \\
\hline Share of Protected Areas (2017) & $24.3 \%$ & $12.6 \%$ & $10.5 \%$ & $13.4 \%$ & $10.4 \%$ \\
\hline Share of forest areas (2017) & $19.5 \%$ & $17.1 \%$ & $14.8 \%$ & $41.5 \%$ & $34.6 \%$ \\
\hline Index ${ }^{1}$ of importance of the agriculture (2001) & 2.3 & 1.8 & 1 & 2 & 1 \\
\hline Index of importance of the agri-food industry (2001) & 0.6 & 0.6 & 0.6 & 1 & 1 \\
\hline Index of importance of agrifood system (2001) & 1.8 & 1.4 & 0.9 & 1.7 & 1 \\
\hline Index of importance of the agriculture (2011) & 2.9 & 1.8 & 1 & 2.1 & 1 \\
\hline Index of importance of the agri-food industry (2011) & 0.9 & 0.7 & 0.7 & 1.1 & 1 \\
\hline Index of importance of agri-food system (2011) & 2.2 & 1.5 & 0.9 & 1.8 & 1 \\
\hline Share of farms with geographical indication ${ }^{2}(2017)$ & 0.6 & 2.4 & 2.7 & 10.1 & 11.2 \\
\hline
\end{tabular}

${ }^{1}$ Index of importance is the specialization index. ${ }^{2}$ Protected designation of origin (PDO) or Protected geographical indication (PGI). Source: own elaboration on NSIA data.

Table 3. Economic and tourism features of Inner Areas (IA) in Italy and the Madonie case.

\begin{tabular}{lccccc}
\hline \multicolumn{1}{c}{ Main features } & Madonie & Sicily IA & Sicily & Italy IA & Italy \\
\hline Business density ${ }^{1}$ (2013) & 89.1 & 95.6 & 92 & 102.7 & 101.6 \\
Growth rate of business stock (2013) & -2 & -0.7 & 0.2 & -0.7 & 0.2 \\
Share of foreign companies (2013) & $2.5 \%$ & $5 \%$ & $5.4 \%$ & $6.2 \%$ & $8.2 \%$ \\
Places of cultural interests (2012) & 7 & 113 & 218 & 1732 & 4558 \\
Visitors (2012) & 11,069 & $1,864,111$ & $4,868,306$ & $13,147,189$ & $103,888,764$ \\
Visitors (2015) & 42,261 & n.a. & n.a. & n.a. & $110,567,265$ \\
\hline
\end{tabular}

${ }^{1}$ Registered firms per 1000 people. Source: own elaboration on NSIA data. (n.a.: not available). 
In the Madonie area, there has been an accelerating demographic crisis for decades, with a decrease of $28 \%$ from 1971 to 2017 [73]. Forthe critical issues related to access to essential services, here are the difficulties of the economy: the construction sector is the only one that supports the local economy, while tourism is characterized by a modest capacity and the agri-food sector does not compensate the absence of manufacture.

Between 2016 and 2018, a complex design process started in the area of Madonie [74] within the NSIA program, aimed at identifying the intervention priorities, objectives, and actions, and focused on numerous issues that concerned education, mobility, health, the digital divide, tourism and culture, agriculture, energy, and protection of the territory, within a broad participatory process that declined in over 65 meetings with local stakeholders, scouting activities, and focus groups.

The key objectives of the Madonie intervention strategy have placed the role of agriculture, considered as a clear identity element for its historical role within the local community, at the center of a project of re-territorialization and its enhancement together with the energy issue. In fact, eight wind farms have been active in the area for just under twenty years, producing about 50\% of the energy needs, but the territory does not derive either labor or a lower energy cost [73].

The actions implemented concerned food and environmental education, within projects related to the identity of the area and the enhancement of its vocations and endogenous resources, represented an innovative revival of historical economic vocation.

In terms of energy management in the area, a FabLab has been developed to produce prototypes of renewable energy plants and small-scale hybrid systems to exploit solar energy and biomass.

A local food policy addressed the issues of food security, food education, and short supply chains, focusing on the role of innovation and endogenous resources, in particular, for two local supply chains for wheat and livestock farming. In addition to starting projects for productions at risk of "genetic erosion" and typical food products, such as some local varieties of ancient grains, manna (sap extracted from the bark of the ash and collected for the production of a sweetener that does not change the blood sugar level), honey of a local black bee, the Scillato's apricot, and the bean of Polizzi named "badda".

Actions have also been developed for the access of young farmers to the land, financially supporting the settlement and learning processes. In this process of return to the land and traditional crops, some elderly owners played a fundamental role, which granted their land on free loan, also activating an exchange of knowledge with the new farmers. The positive results have predisposed other owners to the concession of their lands, while some young farmers interested in the themes of permaculture and local and short supply chain look to the Madonite experiences as examples of the economics of relationships that generate new job opportunities.

The rediscovered identity that represented uniqueness and originality, was the key element as shown in the framework, on which some stakeholders focused their interests to create relationships with the place, tracking the path of long-lasting (sustainable) effects. Regarding the place and the community, the results were both economic and social. Therefore, in terms of social essential services, the local school system has been strengthened with the networking of the area's schools.

In the frame of education and research, is the role of the opening of the Astronomical Park, since the Madonie sky is known for the high number of nights in which the sky is scientifically observable. To enhance this feature, the Fly-Eye Telescope, unique in the world, was created for observing and monitoring of space debris and asteroids dangerous for the Earth.

In terms of tourism enhancement, a key role is the Indie Ypsigrock music festival organized in Castelbuono since 1997, with audiences from all over Europa, the first Italian festival nominated for the European Festival Awards. Additionally, the project of the Madonie Geopark, recognized by UNESCO for the geomorphological value and as a geological path [74].

The Ecomuseum of the Madonie, founded in 2017, tells the identities of the territory and aims to raise awareness of the local communities and their history. 
The territorial characteristics of the area can be summarized by looking at some data. Tables $1-3$ provide comparison data of the Madonie area with the Sicilian and national IA. The data were requested from the NSIA and then processed.

Table 1 offers a summary of the characteristics of the area from a settlement, social, and registry point of view, with particular attention to the role of essential services.

Table 2 provides an overview of the weight of agriculture and the agri-food vocation of the IA. Note the role of the areas cultivated in the area and the extensive nature of the agricultural activities.

Finally, Table 3 shows some data available on the production fabric, on cultural sites, and on the presence of visitors.

Finally, a network of home care services for elderly people has been developed, with the aim of making it an area of specialization in the area's regional scene.

\section{Discussion}

The local Madonite communities face the challenge of the future sharing processes of institutional innovation and inter-municipal governance and promote new partnership networks aimed at strengthening the capacity for resilience and development of the territorial system as a "green community". With a holistic, integrated and circular approach, new social innovation processes are activated that are able to capitalize on the results of the experiences gained and stimulate new models of territorial regeneration, experimenting with new intelligent specializations that contribute to reversing the trend towards the emigration of young people and to depopulation.

These are communities that return to put at the center of local action the cohesion and civicness through the care for the people and the care for the landscape of the mountain countryside, recovering the mosaic of territorial knowledge that serves to reason in systemic terms of flows and cycles of matter and energy (air, water, soil, energy) without forgetting the connections between work and income of farmers, healthy food for consumers, beauty of the landscape for tourists, places of entertainment for the inhabitants, and ecosystem services for the whole community.

The decision to focus on an integrated, socially shared and high-quality local food and agriculture system, enhances the connections between food and agriculture, typical products and production landscapes, allowing new forms of interaction between consumers and producers, and the care of environmental resources.

The Madonie's characteristic food production chains are integrated with new applied research and innovation services, aimed at enhancing the characteristics of biodiversity and improving the biological and genetic qualities of the products. The experimentation of new networks in support of supply chains (short and long) allows farms to the possibility of not delocalizing commercial value chains and offering new opportunities for qualified workers.

The wide availability of public and private land, in addition to those confiscated from criminal organizations, is used to attract new young "third millennium peasants", interested in experimenting with new models of multifunctional and regenerative agriculture, which take on the ecological functioning of the territory through educational farms and social networks of animation aimed at building common goods useful to the community.

The decision to experiment with a new integrated model of energy production and consumption, aiming for $100 \%$ of renewable sources, makes the Madonie territory an extraordinary laboratory of "oil-free zone" innovation, committed to creating new cognitive chains to support new dimensions of sustainable development.

The communities decide to share the advantages of simultaneously playing the roles of consumers and producers, benefiting from the cost savings of energy bills, and the opportunity to invest in the plants of the new network with forms of widespread shareholding.

Figure 5 summarizes the interventions and actions developed in the Madonie area. The rural identity recovered through the set of projects launched, recovering the endogenous resources of the community and its relationship with the territory characterized by a renewed authenticity that 
translates into destinations. The whole of this process determines in the medium- and long-term, the territorial resilience and then, the sustainability of the local development processes.

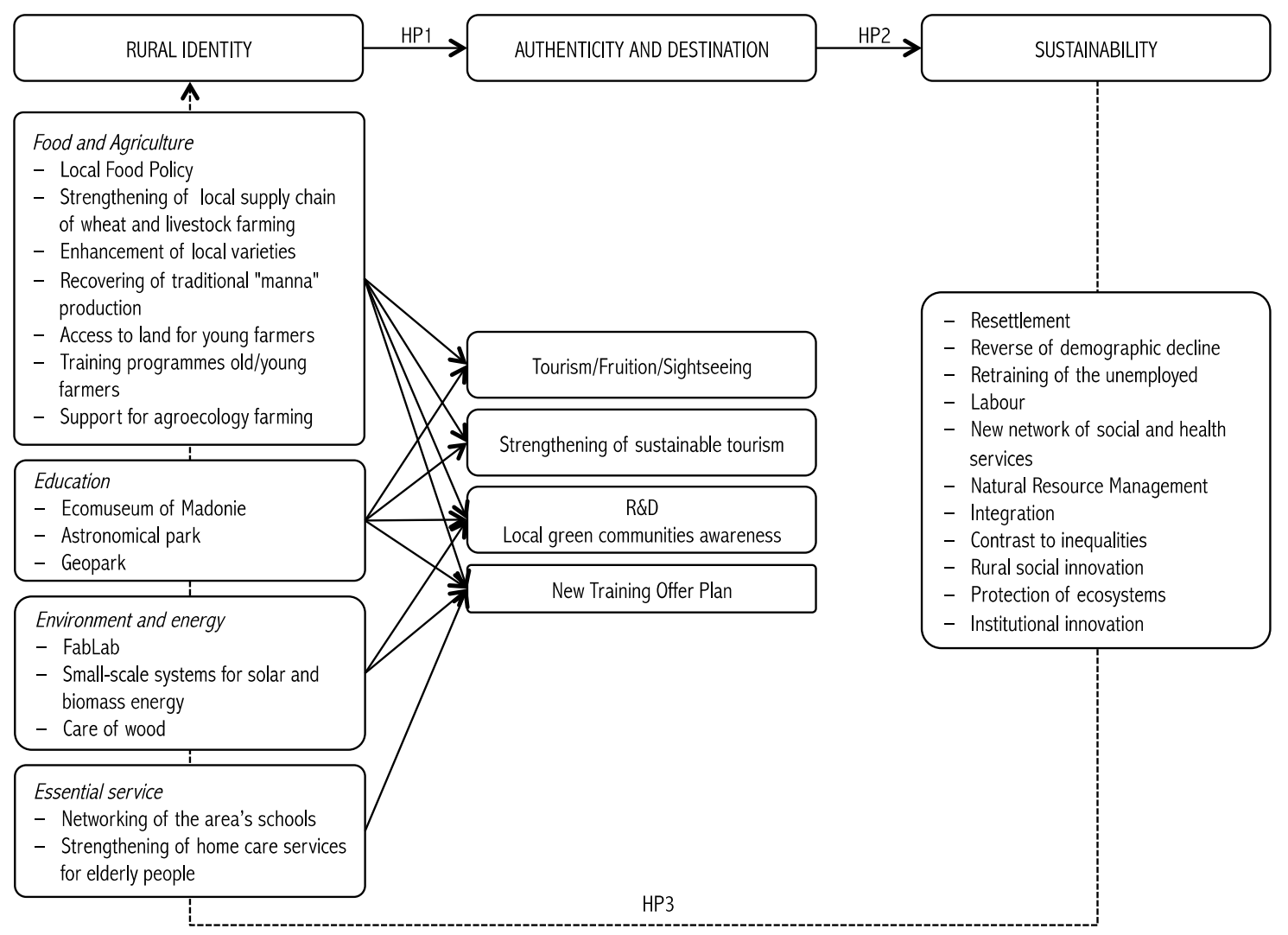

Figure 5. The framework applied in the Madonie case. Source: own elaboration.

The relations between identity, authenticity, and sustainability in the case of Madonie should be summarized as follows:

1. Identity and Authenticity

The development of sustainable tourism is supported by the choice of experimenting with a Destination Management Community, which leverages the wealth of opportunities for relations with local communities, repositories of knowledge and lore capable of transforming the time of a vacation into an unforgettable experience to tell. The Ecomuseum of the Madonie, through community maps, helps to build new forms of narration of an ancient and unique territory, where you can recover the slow pace of life in nature and cultivate the pleasure of travel and return.

2. Authenticity and Sustainability

The territorial resilience processes are supported by widespread intelligent technologies, which allow the organization of networks for continuous monitoring of the risks of hydrogeological instability through forms of active participation of citizens who experience the role of the green community. The local communities support the organization of the Madonie school network and the commitment to adopt a common Territorial Training Offer Plan aimed at innovating the educational and training paths with new connections between the culture of thinking and that of doing and new experiences of school/work alternation. The orientation towards science and mathematics is supported by the extraordinary patrimony of nature and biodiversity and by the endowment of territorial structures of excellence such as the UNESCO Geopark and the Madonie Astronomical Park.

The ability of communities to care for elderly and frail people becomes a professional specialization in support of new networks of social and health services that integrate health and wellness, quality of social relations and lifestyles, in a context of the serene beauty of natural and human landscapes. 
The development of an innovative wireless digital network model provides new broadband connection capacities to institutions, professionals, and companies, multiplying the opportunities for interaction of the territory with the complexity of networks in the contemporary world.

3. Sustainability and Identity

These efforts have begun to give the first signals, bringing the area to a level of employment of the population aged $15-64$ years between $55-60 \%$. These figures are aligned with the national trend and are higher than the average in Southern Italy; additionally, they are above regional and provincial figures, set at around $39 \%$.

From this perspective, rural landscapes constitute a concentration of rules, of autonomous reproduction of productive resources, of strengthening regional identities, such as to provide a valid contribution to overcoming social and economic models. From an administrative and organizational point of view, to reach these objectives, around 20 municipalities have decided to " ( . . ) reorganize the administrative and governance structure of the territory through the establishment of a new Union of Municipalities of the Madonite Inner Area with administrative competences adequate to address, in an integrated manner, the problems of organization and management of services related to citizenship rights".

The achievement of these meta-goals is conditioned both by the aggregative attitude of the territories and by the ability of the system, the result of aggregation, to interact, through identified and/or created sub-systems, with European and National financial interlocutors/stakeholders, as well as regional and private financiers, and to stimulate the bottom-up creation of further sub-systems with goals consistent with the meta-objectives.

Therefore, the aim is to bring out the elements characterizing the multi-functionality of the rural system, and to combine them with expert knowledge for an appropriate use of technologies, raising the overall productivity towards the "innovated" reconstruction of the peasant production mode, of the networks of small family businesses, and community cooperatives, in order to repopulate within the meaning of historic rural landscapes [69].

Naturally, the reactivation of peasant productive knowledge can represent a basis for integrated ecological territorial planning, giving the farmer the role of producer and negotiator of culture, with which starting ruralization experiences of peri-urban areas, and community democracy experiences. Therefore, the rural entrepreneur is a figure who stimulates scientific research, promotes lifestyles, and activates exchange relationships with extensive territorial networks.

The framework proposed a hypothesis, which could be useful for the policymaker and to contribute to future research in the light of Agenda 2030 on sustainable local development. In this sense, Figure 6 summarizes the discussed hypothesis on the role of rural identity and authenticity in driving sustainable processes and crossed them with the involved objectives of Agenda 2030.

The case of Madonie, for which a further deepening of data and a further articulation of the analytical apparatus is needed, highlighted the importance of the reconstruction of rural identities starting from bottom-up processes in which the communities are both the real agents of creation and, as bearers of their own cultures and in relation to the tangible and intangible components of the territory, participating in that agora, that semantic platform in which the territory and stakeholders interact in order to identify and/or create the conditions to respond to mutual needs.

The research presents the lack of indicators or quantitative expressions that could better represent the case. The availability of updated data and the possibility of cross-referencing and comparing sources, both at the national and European levels, represent a limit to research developments. We tried to limit these shortcomings, due to the lack of accurate information, using a qualitative research method. Furthermore, the quantitative measure of the case study represents the current limit of the paper: both for the difficulty of finding data and for the fact that the start of the projects is still quite recent. Future authors' research efforts will be directed in this direction. In fact, the theoretical hypotheses discussed could be declined through the development of indicators for the evaluation of cohesion policies and for policies in peripheral areas. 


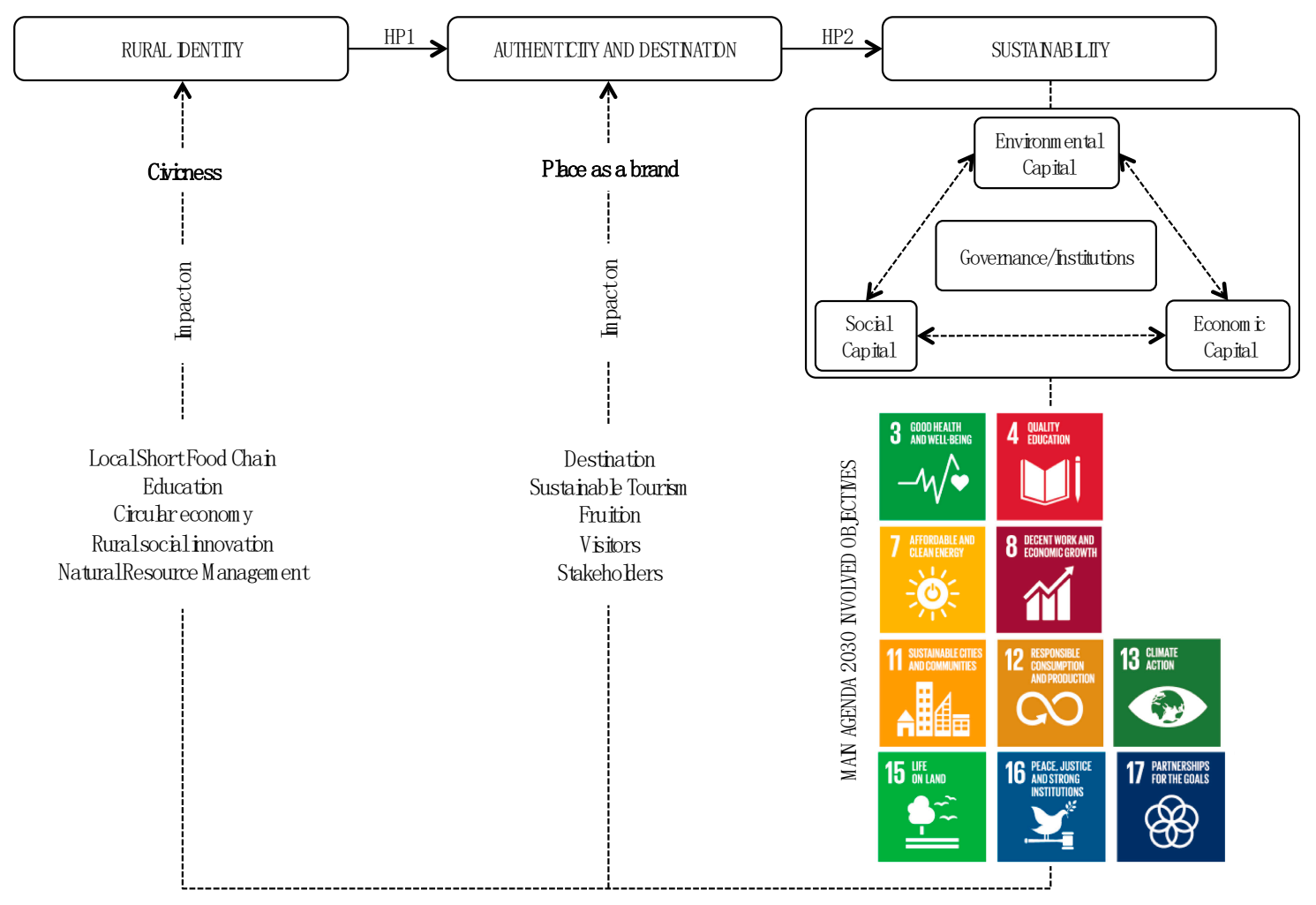

Figure 6. IA in the face of sustainability: the role of identity and authenticity. Source: own elaboration.

Additionally, on the rural identity and the conditions of authenticity, they could be evaluated with positioning analysis and qualitative methods, which can show the degree of authenticity perceived by the stakeholders. As far as sustainability is concerned, both in the scientific and institutional fields, a possibility of developing the themes of the document is linked to the use of indicators. For example, to work on comparable studies at the European level, the BES (Equitable Sustainable Well-Being) currently divided into 12 dimensions and 134 elementary indicators.

The analysis of the relationships linking identity and authenticity to sustainability introduces a dynamic variable to the system, where the probability of exogenous perturbations i.e., immigration, variation of markets and prices, public policies, or endogenous perturbations, for example, emigrations, hydrogeological fragility, infrastructural developments, determine the risk of alterations or changes to local balances. In this direction, it is clear that the capacity for response and territorial regulation, and its social, economic or environmental dynamics, will be much greater as the structural and functional variety of the territorial context.

Identity and authenticity, in the authors' interpretation, establish a relationship with the territorialization and de-territorialization processes [33]. If the latter represents the process of fragmentation of relations and socioeconomic factors of a territory, that determines a structural crisis of the territory itself, re-territorialization represents the process by which the territorial system reconstitutes resilience and cohesive force.

\section{Conclusions}

In the peripheral and marginal areas, the rural-urban divide marks the global scene, in Europe, these processes are reflected in profound social and economic transformations that are the cause of political reversals. A gap linked to deep territorial inequalities in which citizens of rural areas are penalized in public and private services as well as in their investment choices, in territories that are disappearing. The Italian experience of the IA and the case of Madonie show the regenerative and innovative potential of these areas, which could stop and reverse the on-going degeneration. 
The IA and the Italian experience can represent a sustainable territorial model of development and application of innovative policies. The essay has discussed the dynamics that govern the sustainable development of IA areas that represent social and economic difficulties.

We have tried, through a reasoned literature review and a discussion on a territorial case study, to understand the conditions of connection between the rural identity and perceptive components of authenticity in order to cause a positive relapse of the territory's fruition level on the socioeconomic conditions influencing, in turn, the level of sustainability of development.

In the case of the Madonite experience, the re-emergence of identity (for instance, the creation of the Ecomuseum), the creation of a space for comparison and the relative perceptions (brand and authenticity), become the basis for a sustainable economic development of the depressed areas, which has the social component as both a relapse-due to a cybernetic process-and cause of a new process.

The paper, therefore, has proposed a contribution to the advancement of the study strands of a marketing place and local sustainable development, especially in that of the place brand and agricultural economics, as well as of the natural and cultural tourism marketing, confirming and enriching the numerous works that support the active role of the communities and economic agents in the domain of sustainable development of rural territory.

Within the framework of relations between levels of government of the territory (European Union, Parliament, Region, and others) and in the area of strategic planning for identifying specific policies and actions in the future rural areas agenda, which often show conditions of backwardness, this contribution has tried to bring out some elements of address.

In the developments discussed in the paper, the role of recognition of rural identity and authenticity emerges in the context of policy action. Place-based policies [31] aimed at the production of collective goods are placed in this direction to contribute to the demographic reversal and repopulation of these areas.

The paper has attempted to explain the nexus between rural identity and perceptive components of authenticity, and the recursive process, through which reflecting on the destination becomes preconditions to catalyze sustainable local development processes, could be declined, through the development of indicators for the evaluation of cohesion policies and for policies in peripheral areas.

In the direction of restoring centrality to territorial specificities, as a distinctive element of policy action, the Lisbon agenda and subsequently that of the 2020 Strategy have introduced important innovations. Probably, in this direction, it is useful to promote an integration between the so-called people-based policies or place-neutral policies [6] linked to mobility, education, and the so-called place-based policies [31] related to employment, rural development, knowledge diffusion, innovation and a place-sensitive perspective [39], which combines an individual perspective with a territorial one to address the multiple development trajectories.

Author Contributions: This paper is the result of a parenthetical contribution of the authors to the research design and conceptual framework. A.C. wrote the Sections 3.1 and 3.2 on rural identity and agricultural economics and Section 4, G.B. Sections 3.3 and 3.4 on authenticity and place brand. The remaining sections are the result of a common reflection and writing. The authors read and approved the final manuscript. All authors have read and agreed to the published version of the manuscript.

Funding: This research received no external funding.

Conflicts of Interest: The authors declare no conflict of interest.

\section{References}

1. Capello, R.; Caragliu, A.; Fratesi, U. Spatial heterogeneity in the costs of the economic crisis in Europe: Are cities sources of regional resilience? J. Econ. Geogr. 2015, 15, 951-972. [CrossRef]

2. Palaskas, T.; Psycharis, Y.; Rovolis, A.; Stoforos, C. The asymmetrical impact of the economic crisis on unemployment and welfare in Greek urban economies. J. Econ. Geogr. 2015, 15, 973-1007. [CrossRef] 
3. Dijkstra, L.; Garcilazo, E.; McCann, P. The Effects of the Global Financial Crisis on European Regions and Cities. J. Econ. Geogr. 2015, 15, 935-949. [CrossRef]

4. Fratczake, E.Z. The Demographic Crisis and Global Migration. Pap. Glob. Chang. 2016, 23, 71-87. [CrossRef]

5. Batsaikhan, U.; Darvas, Z.; Gonçalves Raposo, I. People on the Move: Migration and Mobility in the European Union; Bruegel: Brussels, Belgium, 2018.

6. Barca, F.; Casavola, P.; Lucatelli, S. Strategia Nazionale per le aree interne. Definizioni, obiettivi e strumenti di governance; Materiali UVAL: London, UK, 2014; p. 31.

7. Costa, J.A.; Bamossy, G.J. Le Parc Disney: Creating an Authentic@ American Experience; ACR North American Advances: Columbus, OH, USA, 2001.

8. Pratt, M.L. Imperial Eyes: Travel Writing and Transculturation; Routledge: London, UK, 1992.

9. De Rossi, A. (Ed.) Riabitare l'Italia; Donzelli: Roma, Italy, 2018.

10. Gustafson, P. Meanings of place: Everyday experience and theoretical conceptualizations. J. Environ. Psychol. 2001, 21, 5-16. [CrossRef]

11. Houghton, J.P.; Stevens, A. City Branding and Stakeholder Engagement, City Branding: Theory and Cases; Dinnie, D.K., Ed.; Palgrave Macmillan Ltd.: London, UK, 2010; pp. 45-53.

12. Therkelsen, A.; Halkier, H.; Jensen, O.B. Branding Aalborg: Building community or selling place? In Towards Effective Place Brand Management; Ashworth, G., Kavaratzis, M., Eds.; Edward Elgar Cheltenham: Northampton, MA, USA, 2010.

13. Battino, S.; Lampreu, S. The role of Sharing economy for a sustainable and innovative development of rural areas: A case study in Sardinia (Italy). Sustainability 2019, 11, 3004. [CrossRef]

14. Urso, G.; Modica, G.; Faggian, A. Resilience and Sectoral Composition Change of Italian Inner Areas in Response to the Great Recession. Sustainability 2019, 11, 2679. [CrossRef]

15. Van der Ploeg, J.D. The New Peasantries: Struggles for Autonomy and Sustainability in an Era of Empire and Globalization; Earthscan: Sterling, VA, USA; London, UK, 2009.

16. Shucksmith, M. Young People and Social Exclusion in Rural Areas. Sociol. Rural. 2004, 44, 43-59. [CrossRef]

17. Commins, P. Poverty and Social Exclusion in Rural Areas: Characteristics, Processes and Research Issues. Sociol. Rural. 2004, 44, 60-75. [CrossRef]

18. Banini, T.; Pollice, F. Territorial identity as a strategic resource for the development of rural areas. In Semestrale di Studi e Ricerche di Geografia XXVII; Sapienza University: Rome, Italy, 2015; Volume 1.

19. Sørensen, J.F. Rural-urban differences in life satisfaction: Evidence from the European Union. Reg. Stud. 2014, 48, 1451-1466. [CrossRef]

20. Bevilacqua, P. Felicità d'Italia; Laterza: Roma-Bari, Italy, 2017.

21. Bandini, M. Economia agrarian; Utet: Turin, Italy, 1968.

22. Rossi Doria, M. Scritti sul Mezzogiorno; Einaudi: Torino, Italy, 1982.

23. Cannata, G. (Ed.) I Sistemi Agricoli Territoriali Italiani; Franco Angeli: Milan, Italy, 1989.

24. Storti, D. Tipologie di Aree Rurali in Italia, 1st ed.; Studi \& Ricerche INEA: Roma, Italy, 2000.

25. Cersosimo, D.; Ferrara, A.R.; Nisticò, R.; De Rossi, A. (Eds.) L'Italia dei pieni e dei vuoti. In Riabitare l'Italia; Donzelli: Roma, Italy, 2018.

26. Bagnasco, A. Tre Italie. La Problematica Territoriale Dello Sviluppo Italiano; Il Mulino: Bologna, Italy, 1997.

27. Becattini, G. Distretti industriali e made in Italy. Le Basi Socioculturali del Nostro Sviluppo Economico; Bollati Boringhieri: Turin, Italy, 1998.

28. Dematteis, G. (Ed.) Il Fenomeno Urbano in Italia. Interpretazione, Prospettive, Politiche; Franco Angeli: Milano, Italy, 1992.

29. Morgan, K.; Waite, D. City deals in the polycentric state: The space and politics of metrophilia in the UK. Eur. Urban Reg. Stud. 2018. [CrossRef]

30. Florida, R. Class-Divided Cities; London Edition; Citylab: London, UK, 2013.

31. Barca, F. An Agenda for a Reformed Cohesion Policy. Independent Report Prepared at the Request of Danuta Hübner; Commissioner for Regional Policy: Bruxelles, Belgium, 2009; Available online: https://ec.europa.eu/regional_ policy/archive/policy/future/pdf/report_barca_v0306.pdf (accessed on 27 August 2019).

32. Meloni, B. (Ed.) Aree Interne e Progetti D'area; Rosenberg \& Sellier: Turin, Italy, 2018.

33. Raffestin, C. Territoriality: A reflection of the discrepancies between the organization of space and individual liberty. Int. Political Sci. Rev. 1984, 5, 139-146. [CrossRef] 
34. Paniuagua, A. Rurality, identity and morality in remote rural areas in northern Spain. J. Rural Stud. 2014, 35, 49-58. [CrossRef]

35. Hoggart, R. A Local Habitation: Life and Times; Random House: New York, NY, USA, 2015; Volume 1.

36. Di Donato, B.; Cavallo, A.; Guadagno, R.; Marino, D. Between City and countryside: Changing nexus in the Urban Phenomenon of Rome. In Peri-Urban Areas and Food-Energy-Water Nexus; Colucci, A., Magoni, M., Menoni, S., Eds.; Springer: Berlin/Heidelberg, Germany, 2016; pp. 117-124.

37. Bock, B. Rural marginalisation and the role of social innovation; a turn towards nexogenous development and rural reconnection. Sociol. Rural. 2016, 56, 552-573. [CrossRef]

38. Cloke, P.; Marsden, T.; Mooney, P. The Handbook of Rural Studies; Sage: London, UK, 2006.

39. Iammarino, S.; Rodríguez-Pose, A.; Storper, M. Regional Inequality in Europe: Evidence, Theory and Policy Implications; Papers in Evolutionary Economic Geography (PEEG) 1817; Utrecht University: Utrecht, Holland, 2018.

40. Cavallo, A.; Di Donato, B.; Guadagno, R.; Marino, D. Cities, agriculture and changing landscapes in urban milieu: The case of Rome. In Rivista di Studi sulla Sostenibilità; Franco Angeli: Milan, Italy, 2015.

41. Becattini, G.; Omodei Zorini, L. Identità locali rurali e globalizzazione. La Quest. Agrar. 2003, 1, 7-30.

42. Romano, D. I Sistemi Locali di Sviluppo Rurale (Slsr); Rapporto Cnel, L'agricoltura Tra Locale e Globale; CNEL: Rome, Italy, 1998.

43. Mastronardi, L.; Marino, D.; Cavallo, A.; Giannelli, A. Exploring the Role of Farmers in Short Food Supply Chains: The Case of Italy. Int. Food Agribus. Manag. Rev. 2015, 18, 109-131.

44. Becattini, G. La Coscienza di Luogo; Donzelli: Rome, Italy, 2015.

45. Cersosimo, D.; Donzelli, C. L'identità come risorsa. Meridiana 2000, 37, 33-55.

46. Bertolini, P.; Pagliacci, F. Quality of life and territorial imbalances. A focus on Italian inner and rural areas. Bio-Based Appl. Econ. J. 2017, 6, 183-208.

47. Campisi, D.; Gitto, S.; Morea, D. Shari'ah-compliant finance: A possible novel paradigm for green economy investments in Italy. Sustainability 2018, 10, 3915. [CrossRef]

48. Castéran, H.; Roederer, C. Does authenticity really affect behavior? The case of the Strasbourg Christmas Market. Tour. Manag. 2013, 36, 153-163. [CrossRef]

49. Sidali, K.L.; Hemmerling, S. Developing an authenticity model of traditional food specialties: Does the self-concept of consumers matter? Br. Food J. 2014, 116, 1692-1709. [CrossRef]

50. Sims, R. Food, place and authenticity: Local food and the sustainable tourism experience. J. Sustain. Tour. 2009, 17, 321-336. [CrossRef]

51. Wang, Y. Customized authenticity begins at home. Ann. Tour. Res. 2007, 34, 789-804. [CrossRef]

52. Chang, R.C.Y.; Kivela, J.; Mak, A.H.N. Food preferences of Chinese tourists. Ann. Tour. Res. 2010, 37, 989-1011. [CrossRef]

53. Hillel, D.; Belhassen, Y.; Shani, A. What makes a gastronomic destination attractive? Evidence from the Israeli Negev. Tour. Manag. 2013, 36, 200-209. [CrossRef]

54. Newman, G.E.; Dhar, R. Authenticity is contagious: Brand essence and the original source of production. J. Mark. Res. 2014, 51, 371-386. [CrossRef]

55. Pine, B.J.; Gilmore, J.H. Authenticity: What Consumers Really Want; Harvard Business School Press: Boston, MA, USA, 2007.

56. Yu, H.; Littrell, M.A. Product and process orientations to tourism shopping. J. Travel Res. 2003, 42, 140-150. [CrossRef]

57. Goulding, C. The museum environment and the visitor experience. Eur. J. Mark. 2000, 34, 261-278. [CrossRef]

58. Chabra, D.; Healy, R.; Sills, E. Staged authenticity and heritage tourism. Ann. Tour. Res. 2003, 30, 702-719. [CrossRef]

59. Kim, H.; Jamal, T. Touristic quest for existential authenticity. Ann. Tour. Res. 2007, 34, 181-201. [CrossRef]

60. Grayson, K.; Martinec, R. Consumer perceptions of iconicity and indexicality and their influence on assessments of authentic market offerings. J. Consum. Res. 2004, 31, 296-312. [CrossRef]

61. Leigh, T.W.; Cara, P.; Shelton, J. The consumer quest for authenticity: The multiplicity of meanings within the MG subculture of consumption. J. Acad. Mark. Sci. 2006, 34, 481-493. [CrossRef]

62. Poria, Y.; Reichel, A.; Brian, A. Heritage site management: Motivations and expectations. Ann. Tour. Res. 2006, 33, 162-178. [CrossRef] 
63. Yeoman, I.S.; McMahon-Beattie, U. The experience economy: Micro trends. J. Tour. Futures 2019, 5, 114-119. [CrossRef]

64. Waitt, G. Consuming heritage-perceived historical authenticity. Ann. Tour. Res. 2000, 27, 835-862. [CrossRef]

65. Fornell, C.; Johnson, M.D.; Anderson, E.W.; Cha, J.; Bryant, B.E. The American customer satisfaction index: Nature, purpose, and findings. J. Mark. 1996, 60, 7-18. [CrossRef]

66. Gnoth, J. Tourism motivation and expectation formation. Ann. Tour. Res. 1997, 24, 283-304. [CrossRef]

67. Hughes, G. Authenticity in Tourism. Ann. Tour. Res. 1995, 22, 781-803. [CrossRef]

68. Kolar, T.; Zabkar, V. A consumer-based model of authenticity: An oxymoron or the foundation of cultural heritage marketing? Tour. Manag. 2000, 31, 652-664. [CrossRef]

69. Basile, G.; Dominici, G.; Tani, M. Place Marketing and Management: A Complex Adaptive Systems View. The Strategic Planning of the City of Avellino, Italy. Syst. Pract. Action Res. 2016, 29, 469-484. [CrossRef]

70. Zenker, S.; Braun, E. Branding a City: A Conceptual Approach for Place Branding and Place Brand Management. In Proceedings of the 39th EMAC Annual Conference 2010, Frederiksberg, Denmark, 1-4 June 2010.

71. Gambetti, R.C.; Graffigna, G. Consumer Brand Engagement: Lo stato dell'arte. Teoria, applicazioni, prospettive di ricerca. Micro Macro Mark. 2011, 20, 199-226.

72. Marsden, T.; Banks, J.; Bristow, G. The social management of rural nature: Understanding agrarian-based rural development. Environ. Plan. A 2002, 34, 809-825. [CrossRef]

73. Barca, F.; Zabatino, A.; Le Madonie. Viaggio in Italia; Il Mulino: Bologna, Italy, 2017; pp. 103-106.

74. Unione dei Comuni delle Madonie, Strategia d'area (Various Documents). 2017. Available online: https: //madonieareainterna.it/verso-strategia/ (accessed on 26 December 2019).

(C) 2020 by the authors. Licensee MDPI, Basel, Switzerland. This article is an open access article distributed under the terms and conditions of the Creative Commons Attribution (CC BY) license (http://creativecommons.org/licenses/by/4.0/). 